\title{
In the Shadows of the COVID-19 Pandemic
}

In this issue of our journal, there are three articles reporting on tuberculosis, a disease which has historically been a big problem in our country - much longer than the current COVID-19 pandemic.

It cannot be denied that COVID-19 is a big problem right now and should indeed be a priority. As of October 24, 2020, the DOH reports that there have been 367,819 cases of COVID-19 from the time it began monitoring the numbers some nearly nine months ago. ${ }^{1}$ The effect of COVID-19 goes beyond these number of cases, as many of them have already died. However, against this alarming situation, even more concern lurks underneath. Just 10 days previously, the WHO released its 2020 Global Tuberculosis Report. ${ }^{2}$ Among other things, prominent mention in the 2020 Report is the threat that the COVID-19 pandemic can reverse the gains made in TB control over recent years in many countries, including the Philippines. In 2019, prior to the COVID-19 pandemic, the Philippines is reported to rank fourth in terms of the number of TB cases, contributing $6 \%$ of the total global burden of TB. ${ }^{3}$ Computing this on a per capita basis paints an even darker picture: the Philippines has $554 \mathrm{~TB}$ cases per 100,000 population, exceeded worldwide only by Lesotho, a small country in Southern Africa with a population of just around $2 \%$ that of the Philippines. ${ }^{4}$

Identifying new TB cases is a key strategy in TB control. It is an important step in identifying and initiating treatment for those who need it. However, gaps in estimated incidence and notifications have long been a problem in the Philippines. ${ }^{2,3}$ And with the COVID-19 pandemic, this has now become bigger. The 2020 WHO Report says that there has been a drop of 50 to $75 \%$ in the monthly notifications for the April to June period compared to January 2020 in the Philippines. Such a trend - reported in other countries as well - is attributed to under-reporting of new TB cases during this COVID-19 pandemic. ${ }^{5-13}$ The sudden drop over a few months cannot be due to any sudden improvement of TB control but more to the challenges that the pandemic has had on the TB control programs. In many TB high burden but low-income countries like the Philippines, reallocation of human, financial and other resources from TB to the COVID-19 response is happening. For example, GeneXpert ${ }^{\mathrm{TM}}$ machines are being diverted for use in COVID-19 testing. ${ }^{14}$ Staff in national TB programs as well as healthcare frontliners are being assigned to COVID-19 related duties. Similar to other countries, community lockdowns, patient concerns on getting infected, lack of public transportation, and loss of jobs and its attendant financial consequences, among others, are also serious considerations limiting access to TB diagnosis and treatment in the Philippines. ${ }^{15}$

Any benefit from social distancing and wearing of face masks to reduce TB transmission are likely outweighed by health service disruption. ${ }^{16} \mathrm{As}$ is the case with other patient co-morbidities, the interaction between COVID-19 and tuberculosis have also been looked into. However, current data do not allow any meaningful conclusions. ${ }^{14,17}$ Because of similarities in presentation symptoms such as fever, cough and difficulty of breathing, the recognition of tuberculosis may also be confused with COVID-19.18,19

All of these are predicted to further worsen TB incidence due to increased transmission and along with greater disease severity will have a larger negative effect on GDP per capita, undernutrition and catastrophic costs to families. ${ }^{2}$ According to the model presented in the 2020 Global TB Report, assuming a more conservative $50 \%$ decrease in case detection over a six-month period could result in 700,000 excess deaths due to TB, globally. ${ }^{2}$ The economic burden of additional cases has also been estimated for other countries and is quite substantial. ${ }^{20}$

In an article published in this issue of our journal, drug resistance is identified as the biggest risk for unsuccessful treatment outcomes in patients with tuberculosis. ${ }^{21}$ There are already increasing RR/MDR TB cases in the country based on the results of the 2016 National TB Prevalence Survey and other data., ${ }^{2,42}$ Previous unsuccessful treatment continues to be a big driver in the development of this drug resistance; and unsurprisingly, we now see that drug resistance in turn further drives even more unsuccessful TB treatment.

In the latest WHO country profile report, RR/MDR TB incidence is estimated at $3.8 \%$ overall; but shoots up to $28 \%$ in previously treated cases. ${ }^{23}$ Most importantly, success of treatment was reported in only 58\% of RR/MDR TB cases started on second-line drugs. As MDR-TB becomes more prevalent, and person-to-person transmission becomes more common, we may soon end up with MDR-TB as a major initial presentation of TB in our country. This is definitely undesirable as treatment of MDR-TB requires significantly more financial resources compared to DS-TB and can further strain the already limited resources allocated for TB control in our country. 
With the big challenges we face with the COVID-19 pandemic and the resulting effect it presents to ongoing TB control, it is reasonable to fear that we will have more unsuccessful treatment of TB in the country. Even as this potentially increases the number of TB cases in general, the even greater threat of further increasing MDR-TB should make us even more concerned. We cannot afford to lose focus and momentum in our efforts to control TB. Others have in fact stated that the current pandemic may actually be a good opportunity to evaluate and if needed, to revise some of the programs we have in TB control. ${ }^{24,25}$ The $\mathrm{WHO}$ has also made some recommendations which we can hopefully follow as we maintain our vigilance on $\mathrm{TB}$ control during this pandemic. ${ }^{26}$

The 2020 WHO Global Tuberculosis Report highlights many of the gains we have made in the Philippines. Hopefully, this COVID-19 pandemic will not push it back.

\section{Joven Q. Tanchuco, MD, MHA Editor-in-Chief Acta Medica Philippina}

\section{REFERENCES}

1. COVID 19 Case Tracker. DOH COVID 19. Case Bulletin \# 224 [Internet]. [cited 2020 Oct 25]. Available from: https://www.doh. gov.ph/covid-19/case-tracker

2. Global tuberculosis report 2020. Geneva: World Health Organization. License: CC BY-NC-SA 3.0 IGO [Internet]. 2020 [cited 2020 Oct 25]. Available from: https://www.who.int/tb/publications/global_ report/en/

3. Global tuberculosis report 2019. Geneva: World Health Organization; License: CC BY-NC-SA 3.0 IGO.

4. Tanchuco JQ. Risk factors, molecular mechanisms and testing of drug resistance in Mycobacterium tuberculosis: Focus on the Philippines. Philipp J Intern Med. 2020; 58(3):72-105.

5. Jain VK, Iyengar KP, Samy DA, Vaishya R. Tuberculosis in the era of COVID-19 in India. Diabetes Metab Syndr. 2020 Sep-Oct; 14(5):1439-43. doi: 10.1016/j.dsx.2020.07.034.

6. Amimo F, Lambert B, Magit A. What does the COVID-19 pandemic mean for HIV, tuberculosis, and malaria control? Trop Med Health. 2020; 48:32. https://doi.org/10.1186/s41182-020-00219-6

7. Ong CWM, Migliori GB, Raviglione M, Mac Gregor-Skinner G, Sotgiu G, Alffenaar J, et al. Epidemic and pandemic viral infections: impact on tuberculosis and the lung. Eur Respir J. 2020; 56(4):2001727. https://doi.org/10.1183/13993003.01727-2020

8. Fei H, Yinyin X, Hui C, Ni W, Xin D, Wei C, et al. The impact of the COVID-19 epidemic on tuberculosis control in China. The Lancet Regional Health - Western Pacific. 2020; 3:100032 https://doi. org/10.1016/j.lanwpc.2020.100032

9. Komiya K, Yamasue M, Takahashi O, Hiramatsu K, Kadota J, Kato $\mathrm{S}$. The COVID-19 pandemic and the true incidence of Tuberculosis in Japan. J Infect. 2020; 81(3):e24-e25. https://doi.org/10.1016/j. jinf.2020.07.004

10. Togun T, Kampmann B, Stoker NG, Lipman M. Anticipating the impact of the COVID-19 pandemic on TB patients and TB control programmes. Ann Clin Microbiol Antimicrob. 2020; 19(1):21. https://doi.org/10.1186/s12941-020-00363-1

11. Ribeiro VST, Telles JP, Tuon FF. Concerns about COVID-19 and tuberculosis in Brazil: Social and public health impacts. Enferm Infecc Microbiol Clin. 2020; S0213-005X(20)30278-0. https://doi. org/10.1016/j.eimc.2020.08.013

12. Alene KA, Wangdi K, Clements ACA. Impact of the COVID-19 Pandemic on Tuberculosis Control: An Overview. Trop Med Infect Dis. 2020; 5(3):123. https://doi.org/10.3390/tropicalmed5030123

13. Magro P, Formenti B, Marchese V, Gulletta M, Tomasoni LR, Caligaris $\mathrm{S}$, et al. Impact of the SARS-CoV-2 epidemic on tuberculosis treatment outcome in Northern Italy. Eur Respir J. 2020; 56(4):2002665. https://doi.org/10.1183/13993003.02665-2020

14. Karim QA, Karim SSA. COVID-19 affects HIV and tuberculosis care. Science. 2020; 369(6502):366-8. doi: 10.1126/science.abd1072.
15. Adepoju P. Tuberculosis and HIV responses threatened by COVID-19. Lancet HIV. 2020; 7(5):e319-e320. doi: 10.1016/S23523018(20)30109-0.

16. McQuaid CF, McCreesh N, Read JM, Sumner T, Houben RMGJ, White RG, et al. The potential impact of COVID-19-related disruption on tuberculosis burden. Eur Respir J. 2020; 56(2):2001718. https://doi.org/10.1183/13993003.01718-2020

17. Crisan-Dabija R, Grigorescu C, Pavel CA, Artene B, Popa IV, Cernomaz A, et al. Tuberculosis and COVID-19: Lessons from the past viral outbreaks and possible future outcomes. Can Respir J. 2020; 2020:1401053. doi: 10.1155/2020/1401053.

18. Bandyopadhyay A, Palepu S, Bandyopadhyay K, Handu S. COVID-19 and tuberculosis co-infection: a neglected paradigm. Monaldi Arch Chest Dis. 2020; 90(3). doi: 10.4081/monaldi.2020.1437

19. Wingfield T, Cuevas LE, MacPherson P, Millington KA, Squire SB. Tackling two pandemics: a plea on World Tuberculosis Day. Lancet Respir Med. 2020; 8(6):536-8 https://doi.org/10.1016/S22132600(20)30151-X

20. Reid MJA, Silva S, Arinaminpathy N, Goosby E. Building a tuberculosis-free world while responding to the COVID-19 pandemic. Lancet. 2020; 396(10259):1312-3. https://doi.org/10.1016/S01406736(20)32138-3

21. Macatangay IOD, Liao SAS, Dadural JJA, Gagui FJS, Galas AJA, San Antonio RDFA, et al. Factors Associated with Treatment Outcome of Patients with Pulmonary Tuberculosis in the Philippines, 2015 to 2016. Acta Med Philipp. 2020; 54(5):604-11

22. DOH. National Tuberculosis Prevalence Survey 2016 Philippines [Internet]. 2018 [cited 2020 Oct 25]. Available from: http://www. ntp.doh.gov.ph/downloads/publications/Philippines_2016\%20 National\%20TB\%20Prevalence\%20Survey_March2018.pdf

23. WHO. 2020 Global Tuberculosis Report [Internet]. [cited 2020 Oct 25]. Available from: https://worldhealthorg.shinyapps.io/tb_ profiles/?_inputs_\&lan $=\% 22 \mathrm{EN} \% 22 \&$ iso2 $=\% 22 \mathrm{PH} \% 22$

24. Keene C, Mohr-Holland E, Cassidy T, Scott V, Nelson A, Furin J, et al. How COVID-19 could benefit tuberculosis and HIV services in South Africa. Lancet Respir Med.2020; 8(9):844-6. https://doi.org/10.1016/ S2213-2600(20)30311-8

25. Manyazewal T, Woldeamanuel Y, Blumberg HM, Fekadu A, Marconi VC. The fight to end tuberculosis must not be forgotten in the COVID-19 outbreak. Nat Med. 2020; 26(6):811-2. https://doi. org/10.1038/s41591-020-0917-1

26. WHO. Updated WHO Information Note: Ensuring the continuity of TB services during the COVID-19 pandemic [Internet]. 2020 [cited 2020 Oct 25]. Available from: https://www.who.int/docs/ default-source/documents/tuberculosis/infonote-tb-covid-19. pdf?sfvrsn=b5985459_18 